\title{
Las voces hispánicas e hispanoamericanas en el Vocabulario Sul Rio-Grandense de José Romaguera Correa (1898)
}

\author{
Maria Filomena Gonçalves ${ }^{1}$ \\ Universidade de Évora/ECS/DLL, Portugal
}

\begin{abstract}
Resumen
La influencia hispánica e hispanoamericana en el léxico del portugués hablado en Rio Grande do Sul (Brasil) es objeto de una lexicografía específica a partir de mediados del siglo XIX. El Vocabulario Sul RioGrandense, publicado en 1898 por José Romaguera Correa (18631910), en la ciudad de Pelotas, es una de las obras que se dedican a recoger las voces hispanas usadas en la variedad riograndense del portugués brasileño. No es la primera en compulsar el léxico propio de esta región brasileña, aunque es la más extensa. En este trabajo se analiza una muestra de las voces hispanas e hispanoamericanas incluidas en el Vocabulario Sul Rio-Grandense, su tipología, sus definiciones y la marca lexicográfica que las identifica, contrastándolas con obras de la actual lexicografía brasileña y española. La muestra analizada por una parte permitió enmarcar el Vocabulario Sul RioGrandense en la lexicografía brasileña y demostrar, por otra, la conciencia de la variación lingüística en Brasil a finales del siglo XIX y, en concreto, los efectos léxicos de la herencia hispana y del contacto interlingüístico en Rio Grande do Sul.
\end{abstract}


Palabras clave: contacto lingüístico, portugués brasileño, español platense, lexicografía regionalista, Brasil.

Hispanic And Spanish-American Words In José Romaguera Correa’s Vocabulario Sul Rio-Grandense

\begin{abstract}
Spanish and particularly Spanish-American influence on the Portuguese lexicon of Rio Grande do Sul (Brazil) has been the focus of lexicographic study since the middle of the $19^{\text {th }}$ century. The Vocabulario Sul Rio-Grandense, published in 1898 by José Romaguera Correa (1863-1910) in Pelotas, is among one of the many works featuring Spanish words used in Brazilian Portuguese of the Rio Grande do Sul. Even though the Vocabulario is not the first study on this topic, it is the most comprehensive analysis of this kind. In this work, we will analyze samples of Spanish and Spanish-American lexicons included in the aforementioned Vocabulario. Furthermore, we will examine its typology, definitions, and lexicographic marks while comparing them to contemporary Spanish and Brazilian works on lexicography. Interestingly enough, these samples enabled us to place the Vocabulario Sul Rio-Grandense within Brazilian lexicography while, at the same time, they provided a sample of the linguistic variation in Brazil at the end of the $19^{\text {th }}$ century, namely, the lexical influences of Spanish origin as well as the inter-linguistic contacts in the Rio Grande do Sul.
\end{abstract}

Keywords: language contact, Brazilian Portuguese, Spanish of the Río de la Plata, regional lexicography, Brazil.

Recibido: 31/05/19 Aceptado: $16 / 10 / 19$

\title{
INTRODUCCIÓN
}

En los últimos años, el estudio del contacto y de las interferencias entre el portugués y el español, tanto en sus variedades peninsulares como en las americanas -véase la novedosa colectánea publicada por Corbella y Fajardo (2017)-, ha conocido no solo un renovado interés, sino una importante actualización del estado del conocimiento. Así lo demuestran asimismo los distintos proyectos desarrollados en varios países y que, en la pasada década, han tratado de recopilar la bibliografía fundamental sobre 
la lengua y la frontera en la península ibérica (Ferreira 2010, Navas 2017) o documentar varias formas de herencia patrimonial, tanto a un lado como al otro de la frontera luso-española, en regiones peninsulares en las que la cercanía geográfica propició afinidades e intercambios históricos, sociales y culturales a lo largo de los siglos. Esta es la preocupación investigativa que orienta, entre otros, el proyecto FRONTESPO (www.frontespo.org), en cuyo ámbito se recogen y estudian vestigios materiales e inmateriales a ambos lados de la frontera ("la raya").

Por otra parte, en lo que atañe a los contactos entre español y portugués en Sudamérica, cabe resaltar los estudios relativos al contacto en zonas fronterizas de la antigua región del Río de la Plata y el sur de Brasil, y asimismo la situación actual referente tanto a la presencia del portugués en Uruguay (Meirelles 2009) como a la influencia española en tierras brasileñas, investigaciones que vienen llevando a cabo de manera sistemática, desde una perspectiva sincrónica o diacrónica, sobre todo Coll (2009) y Coll y Bertolotti (2017), en la senda de los estudios pioneros de Elizaicín $(1975,1987,1992)^{2}$.

En lo que concierne a la influencia léxica hispana en el sur de Brasil, en especial en Rio Grande do Sul, el registro de esas voces en obras lexicográficas brasileñas se remonta a mediados del siglo XIX, cuando, a tenor de la independencia de Brasil en 1822, la conciencia de la variación lingüística en un territorio tan extenso empieza a plasmarse en obras dedicadas a recoger palabras y expresiones propias de la gran diversidad existente en un país caracterizado por el mestizaje étnico, cultural y, evidentemente, lingüístico.

Centrándose en una de las obras lexicográficas regionalistas de finales del siglo XIX, el objetivo de este trabajo es contribuir precisamente al conocimiento del registro lexicográfico de voces hispanas e hispanoamericanas usadas o conocidas, en aquel periodo, especialmente en la región fronteriza de Rio Grande do Sul con la región platina, puesto que ese registro constituye un marco importante en la historia del léxico riograndense y de las relaciones entre el portugués y el español en América del Sur. En un estudio anterior (Gonçalves 2017), ya se ha analizado cómo los vocabularios de regionalismos -el primero se debe a António Álvares Pereira Coruja (1852)-recogen esas voces y les atribuyen una marca propia, lo que equivale a integrar la herencia hispana y su impronta en el portugués

\footnotetext{
A estos se siguieron muchos otros trabajos dedicados al contacto entre español y portugués en la región fronteriza entre Uruguay y Brasil, como, por ejemplo, Elizaicín (2002a, 2002b, 2003). Para el contacto hispano-portugués en el siglo XIX, en particular en Uruguay, véase Ramírez Luengo (2005, 2006).
} 
de la Provincia de Rio Grande do Sul, actual estado del mismo nombre. Nacido en Rio Grande, Coruja fue, en efecto, el primero en recopilar una colección de voces propias de Rio Grande do Sul, sin darle el título de diccionario ${ }^{3}$ pero señalando ya las palabras de origen español y americano. Sin embargo, quedan por analizar otras obras regionalistas, y aún se carece de trabajos sistemáticos sobre los vocabularios del último tercio del siglo XIX publicados bajo el influjo del nacionalismo lingüístico, de la dialectología europea y de la lexicografía hispanoamericana ${ }^{5}$. Entre esas obras se destaca precisamente el Vocabulario Sul Rio-Grandense (1898), de José Romaguera Correa, que recopila las voces de origen hispano que entran así, por primera vez, en un repertorio léxico de la lengua portuguesa. El objetivo del estudio es, por lo tanto, analizar el registro de esas voces en una obra lexicográfica poco conocida y, asimismo, poner de relieve la contribución de Romaguera Correa al estudio de la herencia hispana en territorio brasileño.

\section{BREVE CONTEXTO HISTÓRICO Y LINGÜÍSTICO DE RIO GRANDE DO SUL}

La presencia del español en Rio Grande do Sul se remonta a los siglos XVIXVII, periodo en que existían reducciones y poblados castellanos en este territorio y eran constantes las disputas entre portugueses y españoles por la posesión de las tierras (Koch 1995). En realidad, según la partición realizada por el Tratado de Tordesillas (1494), el territorio de Rio Grande correspondía a Castilla, lo que explica la presencia de misioneros y militares castellanos en esa región, aunque los límites definitivos entre los territorios controlados por portugueses y castellanos solo se establecieron definitivamente a mediados del siglo XVIII. En las tierras tomadas a los castellanos se crea, en 1760, la Capitanía de Rio Grande de São Pedro, que se constituye como Provincia en 1796. Estas relaciones históricas explican la estrecha conexión de Rio Grande

\footnotetext{
3 Hacia finales del siglo XIX, diccionario nombraba las obras que recogían el léxico general, incluyendo asimismo regionalismos, mientras que vocabulario denominaba un repertorio léxico menos abundante y más específico, si bien este título se usó igualmente en obras generales.

4 Gonçalves $(2016,2017)$ aporta algunas contribuciones.

5 Es el caso del Diccionario de chilenismos, de Zorobabel Rodríguez (1875), que en Brasil tuvo recepción en el Diccionario de Vocabulos Brazileiros (1889), del vizconde de Beaurepaire-Rohan.
} 
con la vecina región del Plata y justifican asimismo la influencia léxica (hispana e hispanoamericana), aunque, más que préstamos o influencias, en lo que concierne a la zona fronteriza al sur de Rio Grande y al norte de Uruguay, las condiciones históricas determinaron la existencia de un "léxico compartido" (Caviglia y Fernández 2007; Caviglia et al. 2008; Coll 2009; Bertolotti y Coll 2014: 83). Cabe resaltar que la herencia hispana se manifiesta en voces asociadas a actividades y prácticas (ganadería sobre todo) que, debido a los cambios socioeconómicos y al estilo de vida más cosmopolita de las ciudades, hoy solo perduran en los ambientes rurales más alejados de las grandes urbes.

Además de la influencia luso-española, en el siglo XIX Rio Grande recibe el influjo de la inmigración alemana e italiana, que añade diversidad al panorama lingüístico de este territorio, si bien en las regiones cercanas a los territorios platenses la antigua herencia hispana perduró e incluso se desarrollaron variedades fronterizas persistentes hasta nuestros días (Carvalho 2014; Bertolotti y Coll 2014). Con todo, hay que tener en cuenta la tipología de las voces hispanas existentes en el portugués brasileño de Rio Grande. Respecto a la naturaleza de los hispanismos que se pueden encontrar en la frontera sur de Rio Grande del Sur con Uruguay, en un estudio dialectológico sobre esa región en particular afirma Altenhofen (2006):

A fronteira sul do Rio Grande do Sul com o Uruguai guarda traços de momentos históricos diversos de ocupação da área e oscilações das fronteiras históricas com o espanhol (...). Isso se observa mais nitidamente no léxico, como atestam Koch (1995), Bunse \& Klassmann (1969) e Rodrigues (1998), os quais registram uma série de hispanismos antigos que poderíamos caracterizar como formas de relicto (Reliktform), por terem sobrevivido à dominação posterior pelo português. São exemplos dessas formas de relicto jugo (= canga), planchar (= passar a ferro), piola (= barbante), esquilar (= tosar), dentre outros. (Altenhofen 2006: 128)

En este contexto histórico, social y lingüístico se produce la publicación de vocabularios regionalistas, obras que, evidentemente, responden a la fuerte identidad de la llamada "pequeña patria"6 - Rio Grande do Sul- frente a la "gran patria" (Lazzari 2004), que es Brasil.

6 La identidad regional y el espíritu nacionalista tienen raigambre en Rio Grande do Sul, ya que entre los años 1835 y 1845 transcurrió la Guerra dos Farrapos o Revolução Farroupilha. Lo que empezó como rebelión contra el gobierno imperial resultó en una declaración de independencia de la República Rio-Grandense. Según informa Houaiss (2001), farrapos 


\section{ROMAGUERA CORREA Y EL VOCABULARIO SUL RIO-GRANDENSE (1898)}

José Romaguera da Cunha Correa nació en 1863 en Santana do Livramento y murió en 1910 en Uruguaiana, es decir, en ciudades fronterizas con territorios de habla hispana (véase el mapa 1). Conocía, por tanto, las voces hispanas introducidas en las hablas riograndenses y pudo recoger directamente muchas otras que no constaban en la Colecção de Vocabulos e Frases da Provincia de S. Pedro do Rio Grande do Sul, publicada en 1852 por el ya citado Coruja en la Revista del Instituto Historico e Geographico do Brasil, y republicada en 1856, en formato de libro ${ }^{7}$, en Londres. Los dos autores riograndenses, que eran contemporáneos, aunque Coruja era mayor que Correa, tenían distintas formaciones: el primero fue un reconocido pedagogo y gramático, mientras que el segundo era médico y se había destacado en la vida pública de Rio Grande, en los ámbitos político, literario y periodístico. Que Correa, aun sin poseer formación filológica, se haya dedicado a recoger el léxico de su patria chica no es de extrañar, si se atiende al contexto de la filología decimonónica, cuyo objeto no se restringía al estudio de fenómenos de orden estrictamente lingüístico, sino que se extendía a otras ramas del conocimiento humanístico e incluso transfería paradigmas de las ciencias naturales al análisis del lenguaje humano y las lenguas. Por otra parte, la variación lingüística y la diversidad de usos de la lengua ni era ni es, evidentemente, un tema reservado a los profesores de lengua, gramáticos, filólogos, lingüistas o intelectuales, sino que atañe a toda la sociedad, aunque muchas opiniones carezcan de fundamentos válidos sobre la estructura de la lengua, los procesos inherentes a su funcionamiento y las relaciones entre variación y cambio. Con todo rigor, Correa no era un filólogo, pero tenía una experiencia lingüística personal que, sumada a su formación intelectual y a las prácticas que observaba en autores de su época, aplicó en el Vocabulario, obra que constituye un testimonio lexicológico, dialectológico y lexicográfico de su época.

('harapos') y farroupilha ('individuo mal vestido, andrajoso') fueron los apodos con que los partidarios del emperador (los legalistas) nombraban tanto a los insurrectos como a la guerra en Rio Grande do Sul.

$7 \quad$ Al ser una edición con tan solo 25 ejemplares no tendría gran repercusión. En 1861 volvió a ser publicado en Río de Janeiro (Nascentes 1992/2003a: 678). Además de Coruja (1852), en la década siguiente Apolinário Porto Alegre publica el Popularium sul-riograndense e o dialeto nacional, obra dedicada a la tradición lingüística y etnográfica de la región. 


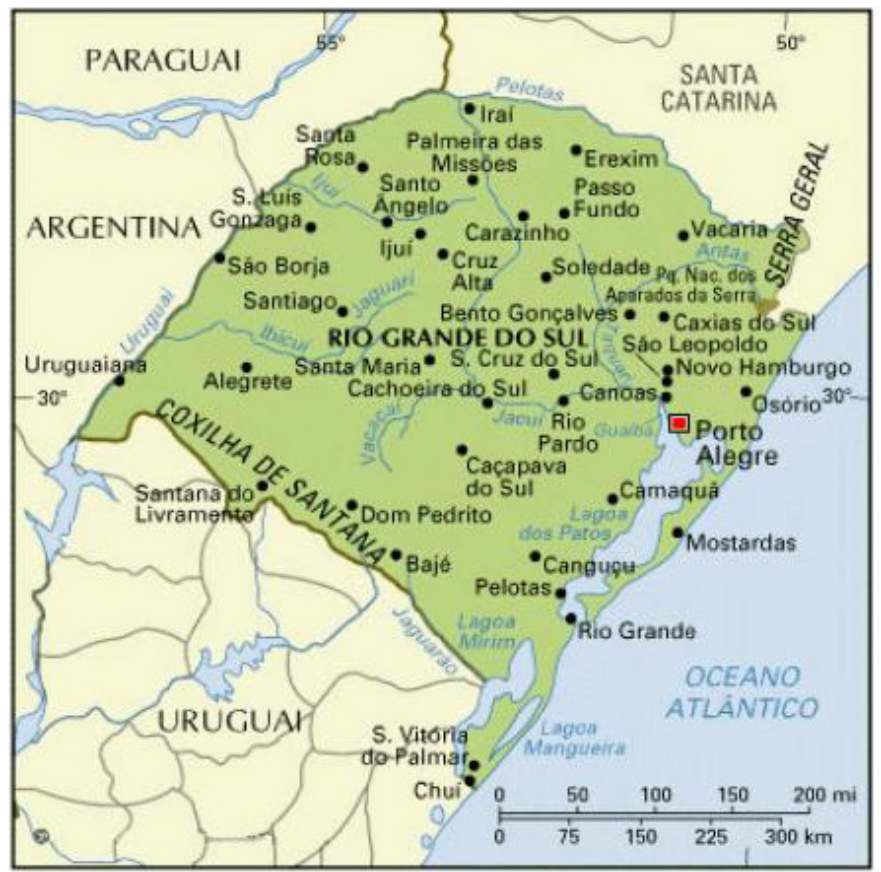

Mapa 1. Santana do Livramento y Uruguaiana ${ }^{8}$

Publicado en Pelotas (véase arriba, mapa 1), el Vocabulario Sul RioGrandense (página siguiente, Imagen 1) de José Romaguera Correa es igualmente una manifestación de la conciencia que, a finales del siglo XIX, ya se tenía de la singularidad léxica del portugués hablado en Rio Grande do Sul, en particular en zonas fronterizas con los territorios del Río de la Plata.

8 Disponible en: https://www.google.com/search?q=mapa+Rio+GRande+do+Sul+san tana + do + livramento $+\mathrm{e}+$ uruguaiana $\&$ tbm $=$ isch\&source $=i u \& i c t x=1 \&$ fir $=$ PLhEAnvtBFoGD M\%253A\%252C6y9f6dysXzk2UM\%252C \&vet=1\&usg=AI4 -kT-RM9qVZOauWMrFu JhquECEC99rg\&sa=X\&ved=2ahUKEwiq-qLQvLLiAhUL8xQK He5zDH0Q9QEwBHoEC AoQBA\#imgrc $=$ zKhn9J9Ifk1LWM:\&vet=1 


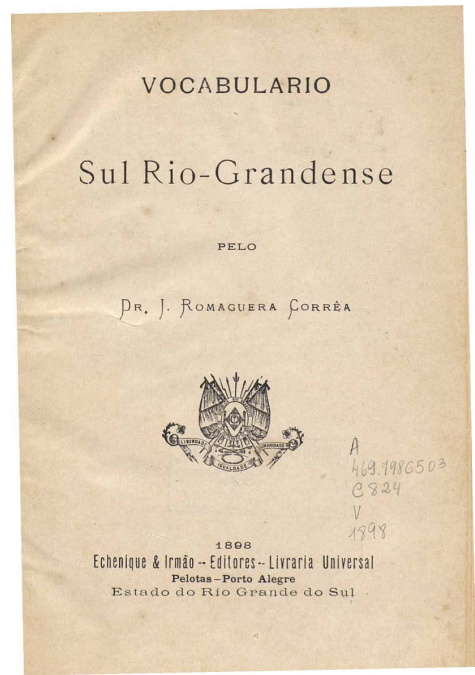

Imagen 1. Portada del Vocabulario Sul Rio-Grandense (1898)

La relación histórica entre esas regiones es tan antigua y estrecha que los habitantes de Rio Grande a sí mismos se llaman "gauchos" y a la variedad riograndense se la conoce popularmente como dialecto "gaucho", expresión alusiva a la herencia hispana que la distingue de otras variedades meridionales de Brasil. Consciente de las improntas dejadas en esas hablas por el antiguo poblamiento del territorio (Koch 1995), Correa describe en el prólogo la mezcla de influencias léxicas, particularmente en zonas fronterizas de Rio Grande do Sul, y que confieren al portugués allí hablado una personalidad propia frente al resto de variedades sureñas de Brasil:

O Rio Grande, desde o seu povoamento, visitado pelos hespanhoes e seus descendentes das margens do Uruguay, em continuo contacto e identificado com estes pela communidade da industria principal, dos costumes, usos, e indole cavalheiresca e altiva; obrigado pela necessidade, e muitas vezes por imitaçào, foi pouco a pouco apossando-se de seus termos e expressões, que, ao lado de vocabulos das linguas incultas - tupi, guarani, quichúa, aztéca, etc., e entremeiados de palavras portuguezas, desvirtuadas de sua vernácula accepção, constituem uma linguagem

9 Según Romaguera Correa (1898: 96), "linguagem gaúcha” es el "dialecto rio-grandense ou mais propriamente o que fallam os camponezes rio-grandenses". 
notavel, pelo cunho original e pittoresco que a distingue da empregada nos outros Estados do Brazil. (Correa 1898: 5)

Cabe resaltar que, descontada la visión que entonces se tenía de las lenguas indígenas (línguas incultas), el autor ofrece un buen retrato del paisaje humano y lingüístico de su región. Pese a haberse ayudado de las obras que presenta en un listado previo a su Vocabulario, el autor pone en valor ante todo su observación (y ciencia propia) de la realidad lingüística de Rio Grande, manifestando por eso la necesidad de corregir informaciones incluidas en obras anteriores: la Colecção de Vocabulos e Phrases usados na Provincia de S. Pedro do Rio Grande do Sul (1852), de Coruja, por una parte, y, por otra, el Diccionario de Vocabulos Brazileiros (1889), de Beaurepaire-Rohan, conforme queda plasmado en el siguiente trecho del prólogo al lector:

Em varias pontos d'este Vocabulário tive ensejos de rebater e rectificar opiniões erroneas e enganos do Visconde de B.-Rohan de veneranda memoria, e do inolvidavel professor Pereira Coruja pois, nascido e tendo convivido por longos annos entre os que se dedicam á industria pastoril e ha muito habitando lugares onde mais caracteristica é a linguagem rio-grandense, conheço-a por observação e sciencia proprias, pouco indagando de fontes estranhas, quasi sempre infieis quanto á definição e emprego dos vocabulos, outro tanto não tendo acontecido áquelles autores que muitas vezes firmaram-se em falsas informações, aliás aceitas de bôa fé. (Correa 1898: 7)

En lo que atañe a la etimología de los hispanismos, Correa aclara que echó mano del Vocabulario Rioplatense Razonado, de Daniel Granada ${ }^{10}$ (18471929), cuya segunda edición, corregida y aumentada, es del año 1890:

Depois de estar concluido este trabalho, chegou-me ás mãos o excelente Vocabulario Rio Platense, do distincto e illustrado Sr. Dr. Daniel Granada, do qual, entretanto, me soccorri algumas vezes, especialmenteno tocante à etymologia e origem de algumas palavras, que, já estando definidas, apresentava faltas quanto à parte etymologica. (Correa 1898: 6)

Pasados más de 50 años desde la publicación del Vocabulario Sul RioGrandense, la dialectología del siglo XX reconocería los méritos de la obra de José Romaguera Correa. En efecto, al enjuiciar la aportación de los

10 De origen gallego, Granada vivió en Uruguay, donde hizo sus estudios y ejerció como letrado y periodista hasta 1904, año en que regresa a España. 
autores que anteriormente habían descrito algunas variedades diatópicas del portugués brasileño, Antenor Nascentes (1952/2003a: 680) -el fundador de la dialectología brasileña- subraya que a Correa se debe la indicación, por primera vez, de la etimología de palabras transmitidas al portugués por el español platense o la procedencia de voces de lenguas indígenas como el tupi, el quechua, el aimara o el araucano. Sin embargo, esos hispanismos, según Nascentes, son insuficientes para dar autonomía a las hablas gauchas del grupo formado por las demás variedades del Sur de Brasil. Nascentes defiende que Rio Grande do Sul, al compartir con São Paulo, Santa Catarina y Paraná varios rasgos fonéticos y una entonación, se agrupe junto a las otras tres en el llamado "dialecto sulista" (Nascentes 1955/2003b: 703). Cabe resaltar que Júlio Ribeiro (1891) ya había anteriormente individualizado la región sur de Brasil respecto a otras grandes regiones del país (Centro, Este y Norte), si bien el criterio de este gramático y filólogo fuera puramente geográfico, mientras que Nascentes proponía una metodología basada en isoglosas, fundada, por ende, en rasgos lingüísticos que representaban verdaderas fronteras lingüísticas. Son estas las que le permitieron identificar el "dialecto sulista", incluyendo en él las hablas de Rio Grande do Sul, puesto que el léxico hispano no determinaba una frontera entre esa región y Paraná o Santa Catarina (Nascentes 1955/2003b: 702-703). A este respecto, Nascentes subraya lo siguiente:

Existe abundancia, não predominância, de termos espanhóis, mas isto não apresenta uma diferença tão grande, tanto mais que o léxico não é o característico dialetal principal. (Nascentes 1955/2003b: 703)

Aun aceptando que buena parte de las voces hispanas e hispanoamericanas usadas en zonas fronterizas de Rio Grande do Sul con territorios vecinos tenían en el siglo XIX una expansión, una vitalidad y una distribución geográfica ${ }^{11}$ y social muy distinta de la que poseen en épocas más recientes -véanse los datos del Atlas Lingüístico de Rio Grande do Sul (Koch et al. 2002; Altenhofen 2006)-, lo cierto es que muchas de esas palabras integraban verdaderos sociolectos, propios de gente que vivía en la campaña y se dedicaba a menesteres como la producción de ganado y caballos, actividad entonces predominante en la economía de la región, como también es cierto que las voces de origen hispano en realidad constituían una terminología patrimonial compartida con la vecina región platense (Uruguay y parte de Argentina). A partir de una muestra, en los siguientes apartados se demostrará

11 Sobre la distribución de los regionalismos, véase Oliveira (2001). 
precisamente el carácter patrimonial y compartido de las voces recogidas en el Vocabulario de José Romaguera Correa.

\section{LAS VOCES ESPAÑOLAS E HISPANAS EN EL VOCABULARIO SUL RIO-GRANDENSE}

El objetivo del Vocabulario es ofrecer un listado de las voces propias de Rio Grande do Sul, aclarando su definición o acepción específica, entre otras que pueda tener cada palabra, y además indicar su procedencia u origen. Como subgénero lexicográfico - diccionario regionalista que resulta de un recorte geográfico de las voces de una lengua-, adopta los principios de un diccionario general, es decir, presenta una macroestructura o nomenclatura y una microestructura o enunciado lexicográfico que se organiza, de manera más o menos sistemática, en paradigmas informacionales relativos a las unidades léxicas y su uso: la clase gramatical y el género; la definición de la unidad léxica que suele ser una descripción del referente nombrado, es decir, una definición extralingüística y, por ende, enciclopédica, pues se refiere al universo de las cosas nombradas, y no a los signos lingüísticos. Después de estas informaciones, aparecen marcas cuya función es, por un lado, distinguir las voces propiamente castellanas de las hispanoamericanas y, por otro, señalar las palabras portuguesas que en Rio Grande poseen una acepción distinta tanto de la lusitana como de la que pueden recibir en otras regiones brasileñas. En efecto, en un primer campo, la micro-estructura presenta la definición de las voces riograndenses, identificando después los hispanismos e hispanoamericanismos mediante una expresión que funciona como marca de procedencia-Es voz del español/Es voz del hispano-americano-, aunque la intención de Correa no es atribuir un étimo propiamente dicho, sino más bien indicar la fuente o el origen de las palabras usadas en Rio Grande do Sul. Con todo, el autor discute, en ciertos casos, la procedencia o el étimo indicado por algún autor.

\subsection{Tipología DE LAS VOCES RIOGRANDENSES}

Las voces recopiladas por Romaguera Correa en su Vocabulario son de dos tipos, ambos justificados por los factores históricos y lingüísticos ya mencionados: por un lado, las palabras que provienen del "castelhano", 
entre las cuales destaca en el prólogo cincerro, hosco, lonca, cadena y, por otro, las de origen hispanoamericano, como pilcha, changa, pulpero, maturrango, churrasco ${ }^{12}$. La consulta de diccionarios actuales de referencia para el portugués -el Dicionário Houaiss da Língua Portuguesa (Houaiss 2001)- y el español -Diccionario de la Lengua Española ${ }^{13}$, de la Real Academia (en línea) - confirma el carácter diatópico (regionalismo de Rio Grande do Sul) de todas esas voces, si bien su uso se extienda igualmente a otras regiones y variedades brasileñas. Además, todas las acepciones indicadas por el autor coinciden con las recogidas en Houaiss (2001), y lo mismo se nota respecto a la procedencia indicada en este diccionario ${ }^{14}, \mathrm{y}$ que corrobora, en su mayor parte, la apuntada en el Vocabulario. Sin discutir aquí la fiabilidad de la etimología aportada por Correa, es decir, la exactitud de la procedencia u origen de las voces, se puede afianzar que el autor no se equivocaba ni respecto a esta ni respecto a sus significados. Cabe asimismo señalar que la base de datos del Houaiss incluye información recopilada de diccionarios portugueses del siglo XIX, y que algunos de los autores de esas obras se sirvieron del Diccionario de Beaurepaire-Rohan como fuente para los brasileñismos ${ }^{15}$.

Para comprobar el acierto de las definiciones de Correa, estas serán contrastadas con la información incluida en los ya citados Houaiss (2001) y $D E L$. Como muestra de las mencionadas dos clases, véanse en primer lugar las palabras que Correa destaca en el prólogo al lector.

12 Aunque el autor presenta los ejemplos exactamente según este orden, en la tabla 1 estos aparecen por orden alfabético.

13 Se eligió este diccionario académico en lugar del Diccionario de Americanismos porque aquel, al ser una obra de referencia del español en general, permite la comparación con el Houaiss que, a pesar de ser brasileño, también es un repertorio general.

14 Se trata de una marcación etimológica en el sentido más riguroso o estricto de "etimología", puesto que el autor del Vocabulario no indica propiamente los étimos de las voces hispanas o hispano-americanas, limitándose a mencionar su procedencia o la lengua de donde provienen, práctica que, en realidad, también es habitual en la lexicografía posterior.

15 El primer listado de voces específicamente brasileñas se debe al Vizconde de Pedra Branca (1780-1855). Lo publicó Balbi (1826) en su Atlas ethnographique du globe, ou classification des peuples anciens et modernes d'après leur langue. 


\begin{tabular}{|c|c|c|}
\hline Vocabulario Sul & \multicolumn{2}{|c|}{ Definición y marca diatópica lexicográfica } \\
\hline Voces & Houaiss & DEL \\
\hline $\begin{array}{l}\text { Cadena subs. f.: (voc. } \\
\text { castelhano que significa - } \\
\text { cadeia). Artificio que usam } \\
\text { os campeiros para tirar o laço } \\
\text { que prende um touro bravio } \\
\text { sem que este possa fugir e } \\
\text { de maneira a ser conduzido } \\
\text { para onde se quizer; o que se } \\
\text { obtem (além de outro meio: - } \\
\text { o de um nó falso) prendendo- } \\
\text { se um laço á argola do que } \\
\text { segura o animal, de modo } \\
\text { que, puxando-se aquelle, } \\
\text { e ste sahe facilm ente, } \\
\text { desmanchando- se a laçada } \\
\text { e sem que então seja preciso } \\
\text { derrubar-se o touro que só } \\
\text { vae ao chão na occasião de } \\
\text { se lhe collocar a - cadena. } \\
\text { (Correa 1898: 40-41) }{ }^{16}\end{array}$ & $\begin{array}{l}\text { (1899) Regionalismo: } \\
\text { Brasil. } \\
\text { nó falso us. para soltar } \\
\text { com facilidade, a distância } \\
\text { e sem perigo, o laço com } \\
\text { que se prende o touro bravo } \\
\text { pelos chifres. esp. cadena } \\
\text { (s XIII). }\end{array}$ & $\begin{array}{l}\text { Del lat. catēna.1. f. Serie } \\
\text { de muchos eslabones } \\
\text { enlazados entre sí, } \\
\text { normalmente metálicos, } \\
\text { que sirve principalmente } \\
\text { para atar, sujetar o adornar. }\end{array}$ \\
\hline $\begin{array}{l}\text { Cincerro subs. masc. - } \\
\text { especie de campainha, porém } \\
\text { maior do que as ordinarias e } \\
\text { que se prende ao pescoço } \\
\text { da egua-madrinha. Ao som } \\
\text { do cincerro, os cavallos, } \\
\text { que acompanham a egua, } \\
\text { procuram reunir-se á ella. } \\
\text { Nos bois de carretas em } \\
\text { viagem costumam collocar } \\
\text { o cincerro em dois ou três. }\end{array}$ & $\begin{array}{l}\text { (1899) Regionalismo: } \\
\text { Minas Gerais, Sul do Brasil. } \\
\text { Sineta que pende do } \\
\text { pescoço de certos animais } \\
\text { (égua madrinha, besta, } \\
\text { vaca), e cujas batidas de } \\
\text { sonoridade indefinida } \\
\text { servem para guiar e reunir } \\
\text { uma tropa, um rebanho. } \\
\text { esp. cencerro (1330) 'id.', } \\
\text { segundo Corominas, de } \\
\text { orig. onom., talvez tomado } \\
\text { do vasco zinzerri. }\end{array}$ & $\begin{array}{l}\text { De or. onomat. } \\
\text { 1. m. Campana pequeña } \\
\text { y cilíndrica, tosca por lo } \\
\text { común, hecha con chapa } \\
\text { de hierro o de cobre, que } \\
\text { se usa para el ganado y } \\
\text { suele atarse al pescuezo de } \\
\text { las reses. }\end{array}$ \\
\hline
\end{tabular}

16 Esta palabra ya había sido recogida en la Colecção de Coruja (1852: 216), cuya definición coincide en lo esencial con la de Correa. 


\begin{tabular}{|c|c|c|}
\hline $\begin{array}{l}\text { - Etym.: deriv. da palavra } \\
\text { castelhana - cencerro. } \\
(\text { Correa } 1898: 58)^{17}\end{array}$ & & \\
\hline $\begin{array}{l}\text { Hosco, a, adj.: pêlo ou côr } \\
\text { de gado vaccum em que se } \\
\text { nota os lados das costellas } \\
\text { vermelhos e o resto do } \\
\text { corpo tostado escuro; outras } \\
\text { vezes, o corpo é todo escuro } \\
\text { carregado, menos a cabeça } \\
\text { que é vermelha. É palavra } \\
\text { castelhana. (Correa 1898: } \\
\text { 104) }\end{array}$ & $\begin{array}{l}\text { (1890) Rubrica: zootecnia. } \\
\text { Regionalismo: Rio Grande } \\
\text { do Sul. } \\
\text { que a presenta pêlo } \\
\text { avermelhado, sendo o } \\
\text { lombo ou a maior parte do } \\
\text { corpo escuro, como que } \\
\text { queimado (diz-se de gado } \\
\text { vacum). esp. hosco (1335) } \\
\text { 'pardo escuro, escuro'. }\end{array}$ & $\begin{array}{l}\text { Del lat. fuscus 'oscuro'. } \\
\text { 3. adj. p. us. Dicho de un } \\
\text { color: Muy oscuro. } \\
\text { 4. adj. p. us. De color hosco. }\end{array}$ \\
\hline $\begin{array}{l}\text { Lonca subst. fem: couro } \\
\text { despido do pelo, couro } \\
\text { lonqueado. - Etym.: do cast. } \\
\text { - lonja (Correa 1898: } 115)^{19}\end{array}$ & $\begin{array}{l}\text { (1889) Regionalismo: Rio } \\
\text { Grande do Sul. } \\
\text { parte do couro do cavalar, } \\
\text { nos flancos desses animais, } \\
\text { da base do pescoço até } \\
\text { as nádegas, que, sem } \\
\text { curtimento, é us. para } \\
\text { fazer tentos ou para retovo. } \\
\text { plat. lonja (a1325) 'tira } \\
\text { de couro, correia larga'; } \\
\text { (1495) 'pedaço largo e fino } \\
\text { de carne e de outras coisas', } \\
\text { este do fr. longe (s. XII) } \\
\text { 'correia' (especialmente } \\
\text { a usada para sujeitar um } \\
\text { animal). }\end{array}$ & $\begin{array}{l}\text { Lonja - con dos acepciones, } \\
\text { pero ninguna de ellas } \\
\text { coincide con la de Correa } \\
\text { o Houaiss }{ }^{20} \text {. }\end{array}$ \\
\hline
\end{tabular}

Tabla 1. Marcación de voces de origen español o hispano

17 Coruja (1852) no la registra, pero esta voz constará después en la nomenclatura de Beaurepaire-Rohan (1889: 48). Este le atribuye origen castellano y señala, como marca diatópica, que era usada en otras regiones además de Rio Grande do Sul: Paraná, São Paulo, Goiás, Minas Gerais y Mato Grosso. Correa no alude a esta distribución geográfica de la palabra.

${ }_{18}$ Aparece en Coruja (1852: 225) cuya obra sirve de fuente a Beaurepaire-Rohan (1889: 73). En castellano, esta voz está atestada desde, por lo menos, el siglo XIV (véase Corpus del Nuevo Diccionario Histórico del Español - CNDHE).

${ }^{19}$ La registra Coruja (1852: 226), citado por Beaurepaire-Rohan (1889: 83), cuyo Vocabulario sirve de referencia cronológica al diccionario Houaiss.

${ }^{20}$ Granada (1890: 260) la recoge como lonja con acepción idéntica a la de los lexicógrafos brasileños: "LONJA, f.- Cuero descarnado y sin pelo". 
Los cuatro ejemplos se inscriben en el dominio semántico y terminológico referente a la crianza de ganado y caballos, actividad que, merced a su tradición e importancia tanto económica como social en Rio Grande do Sul, es la que presta más voces al Vocabulario de José Romaguera Correa. La comparación de los enunciados reunidos en la tabla 1 permite concluir que, según la lexicografía brasileña actual ${ }^{21}$, solo dos de las palabras recogidas en el Vocabulario Sul Rio-Grandense -hosco y lonca- son, de acuerdo con la correspondiente marca de Houaiss, regionalismos de Rio Grande do Sul; de las dos restantes, una (cincerro) está marcada como regionalismo, aunque no exclusivo del sur de Brasil-Regionalismo: Minas Gerais, Sul do Brasil-, y la otra (cadena), simplemente como voz brasileña (Regionalismo: Brasil), usada, por lo tanto, en varias regiones del país. Cabe resaltar que solo en un caso (lonca) el diccionario Houaiss toma a Beaurepaire-Rohan (1889) como fuente de registro y datación, mientras que para otras dos palabras (cadena, cincerro) la fuente es el Diccionario de Cândido de Figueiredo (1899), lexicógrafo portugués que, a su vez, la tomó seguramente de Beaurepaire-Rohan. Estas observaciones en torno a la red constituida tanto por la nomenclatura como por los enunciados lexicográficos demuestra las ventajas de una base de datos que, por una parte, incluya los diccionarios generales y asimismo los regionales y, por otra, fuentes textuales muy diversificadas de las varias épocas de la lengua. Los diccionarios son, sin duda, fuentes relevantes, pero no sustituyen a las fuentes más cercanas a la realidad lingüística.

Aunque las voces relativas a la ganadería y la crianza de caballos sean de las más abundantes en el Vocabulario de Correa, se registran igualmente palabras que nombran realidades de ámbitos referenciales muy distintos. La pequeña muestra reunida en la tabla 2 y su registro en diccionarios actuales del portugués y del español, además de ilustrar varios campos semánticos, pone de manifiesto que Romaguera Correa hizo acopio de las voces de regionalismos que tienen origen hispanoamericano y cuyo uso en Rio Grande do Sul es, a tenor de los datos del $D E L$, una extensión de los territorios del Río de la Plata y que, en algunos casos, las palabras circulan en áreas más extensas, no platenses, como sucede con pulpería, que no se restringe al español de la región del Plata.

21 Para una panorámica histórica de la lexicografía brasileña, véase, por ejemplo: Finatto (1993) y Nunes (2006). 


\begin{tabular}{|c|c|c|}
\hline Vocabulario Sul & \multicolumn{2}{|c|}{ Definición y marca lexicográfica } \\
\hline Voces & Houaiss (2001) & DLE \\
\hline $\begin{array}{l}\text { Changa, subs. f. : carreto, } \\
\text { carro que é conduzido por } \\
\text { ganhadores (changadores) } \\
\text { de um ponto a outro; } \\
\text { ganho, lucro: Hoje com } \\
\text { aquelle negocio tive } \\
\text { boa changa. E' voc. da } \\
\text { América do Sul, e assim } \\
\text { os seus derivados, abaixo } \\
\text { mencionados, embora em } \\
\text { Cuba tambem se empregue } \\
\text { este nome mas com outra } \\
\text { significação, de-caçoada, } \\
\text { pilheria. (Campano) } \\
\text { (Correa 1898: } 51-52 \text { ) }\end{array}$ & $\begin{array}{l}\text { (1922) Regionalismo: Rio } \\
\text { Grande do Sul. } \\
\text { negócio vantajoso [...] } \\
\text { segundo Nasc., do plat. } \\
\text { changa 'ocupação ou } \\
\text { serviço prestado pelo moço } \\
\text { de fretes'. }\end{array}$ & $\begin{array}{l}\text { Arg., Par. y Ur. Ocupación } \\
\text { transitoria, por lo común } \\
\text { en tareas menores. } \\
\text { Del gallegoport. changa. }\end{array}$ \\
\hline $\begin{array}{l}\text { Churrasco subs. m.: } \\
\text { pedaço de carne sangrenta } \\
\text { e mal assada sobre as } \\
\text { brazas e labaredas e que } \\
\text { constitue o mais poderoso } \\
\text { alimento dos camponezes } \\
\text { rio-grandenses. É palavra } \\
\text { da America Hespanhola. } \\
\text { (Correa 1898: } 57 \text { ) }\end{array}$ & $\begin{array}{l}\text { (1881) Derivação: por } \\
\text { metonímia. Regionalismo: } \\
\text { Rio Grande do Sul. A rês } \\
\text { que se escolhe para carnear. } \\
\text { plat. churrasco 'id.', } \\
\text { regr. do esp. churrascar, } \\
\text { var. de socarrar (1220) } \\
\text { 'chamuscar, queimar', } \\
\text { de orig. pré-romana e da } \\
\text { mesma procedência que } \\
\text { o vasco ant. e dialetal } \\
\text { sukarr (a) 'chamas, } \\
\text { incêndio'. }\end{array}$ & $\begin{array}{l}\text { Voz onomat. } \\
\text { 1. m. Carne asada a la } \\
\text { plancha o a la parrilla }{ }^{22} \text {. }\end{array}$ \\
\hline $\begin{array}{l}\text { Maturrango, a, adj.: o } \\
\text { que monta mal ou que } \\
\text { não entende de serviços }\end{array}$ & $\begin{array}{l}\text { (1899) Regionalismo: } \\
\text { Rio Grande do Sul. } 1 . \\
\text { indivíduo que não sabe }\end{array}$ & $\begin{array}{l}\text { De matar. 1. adj. Arg., } \\
\text { Perú y Ur. Dicho de una } \\
\text { persona: Que es mal jinete. }\end{array}$ \\
\hline
\end{tabular}

${ }^{22}$ En el Corpus del Nuevo Diccionario Histórico del Español (CNDHE), el primer registro es de 1853 . 


\begin{tabular}{|c|c|c|}
\hline $\begin{array}{l}\text { pastoril. O mesmo } \\
\text { bahiano, em uma das } \\
\text { accepções deste vocabulo; } \\
\text { inhabil, pouco pratico, } \\
\text { bisonho em qualquer } \\
\text { assumpto: } \\
\text { Em negocios de amor, você } \\
\text { ainda está mui maturrango. } \\
\text { Etym.: é voc. hispano- } \\
\text { americano. (Correa 1898: } \\
\text { 128) }\end{array}$ & $\begin{array}{l}\text { montar; mau cavaleiro } 2 . \\
\text { indivíduo ignorante dos } \\
\text { trabalhos relacionados com } \\
\text { o campo 3. inexperiente, } \\
\text { inábil no exercício de } \\
\text { qualquer atividade. Origen } \\
\text { contr. Nascentes deriva } \\
\text { do plat. maturrango 'mau } \\
\text { cavaleiro', que, segundo } \\
\text { Corominas, é der. do esp. } \\
\text { matar 'matar'. }\end{array}$ & \\
\hline $\begin{array}{l}\text { Pilcha subs. f.: joia, adorno; } \\
\text { objectos de algum valor } \\
\text { como arreios, roupas etc. } \\
\text { Desta palavra derivam-se } \\
\text {-empilchar e despilchar. E' } \\
\text { Voc. hispano-americano. } \\
\text { (Correa 1898: } 160)\end{array}$ & $\begin{array}{l}\text { R e gi on a lis mo: Rio } \\
\text { Grande do Sul. 1. qualquer } \\
\text { soma de dinheiro; } 2 . \\
\text { Derivação: por extensão } \\
\text { de sentido. qualquer } \\
\text { objeto que tenha algum } \\
\text { valor; 3. objeto de adorno; } \\
\text { adereço, enfeite: 4. peça de } \\
\text { vestuário, esp. o poncho, } \\
\text { a bombacha, as botas e o } \\
\text { chiripá. } \\
\text { plat. pilcha 'mulher } \\
\text { querida; prenda, presente, } \\
\text { dádiva'. }\end{array}$ & $\begin{array}{l}\text { coloq. Arg., Bol., Par., Perú } \\
\text { y Ur. Prenda de vestir, } \\
\text { particularmente si es } \\
\text { elegante y cara. U. m. en pl. } \\
\text { Del mapuche pulcha } \\
\text { 'arruga'. }\end{array}$ \\
\hline $\begin{array}{l}\text { Ponchada, subs. f.: grande } \\
\text { quantidade de qualquer } \\
\text { coisa e que poderia encher } \\
\text { um poncho: Ganhamos } \\
\text { uma ponchada de moedas. } \\
(\text { Correa } 1898: 382)^{23}\end{array}$ & $\begin{array}{l}\text { m.q. ponchaço (ponchaço } \\
\text { grande quantidade de } \\
\text { coisas, inclusive dinheiro) }\end{array}$ & $\begin{array}{l}\text { 1. f. Arg. Lo que cabe en un } \\
\text { poncho. } \\
\text { 2. f. coloq. Arg., Bol., Par. } \\
\text { y Ur. montón (\| cantidad } \\
\text { considerable). }\end{array}$ \\
\hline
\end{tabular}

23 Respecto a la voz poncho, Correa, citando a Zorobabel Rodríguez (1839-1901), le atribuye un origen araucano (pontho). Así consta, en efecto, en el Diccionario de chilenismos (Rodríguez 1875: 382). Sin mención de la procedencia, esta palabra aparece igualmente en el Vocabulario rioplatense razonado (Granada 1890: 325), obra en que el autor, basado en el vizconde Beaurepaire-Rohan, incluso menciona el uso de esa palabra en Rio Grande do Sul: 


\begin{tabular}{|c|c|c|}
\hline $\begin{array}{l}\text { Pulperia, subs. f.: venda, } \\
\text { casa de negócio, taverna, } \\
\text { etc. E' voc. hispano- } \\
\text { americano. } \\
(\text { Correa } 1898: 169)^{24}\end{array}$ & $\begin{array}{l}\text { Regionalismo: Rio Grande } \\
\text { do Sul. } \\
\text { pequena venda ou taverna } \\
\text { na área rural. } \\
\text { plat. pulpería }(1627)^{25} \\
\text { 'taberna, tenda'; ver } \\
\text { pulpeiro }\end{array}$ & $\begin{array}{l}\text { Arg., Bol., Chile, C. } \\
\text { Rica, Ec., Hond., Méx., } \\
\text { Nic., Perú, R. Dom., } \\
\text { Ur. y Ven. Propietario } \\
\text { o dependiente de una } \\
\text { pulpería (i.e. tienda donde } \\
\text { se venden artículos de uso } \\
\text { cotidiano, principalmente } \\
\text { comestibles). }\end{array}$ \\
\hline $\begin{array}{l}\text { Quincha, subs. f. a coberta } \\
\text { de casa ou carreta, feita de } \\
\text { palha, ou antes, pequenos } \\
\text { pedaços de palha que se } \\
\text { unem uns aos outros sobre } \\
\text { o tecto da casa ou tolda } \\
\text { da carreta (Vocabulario } \\
\text { de A. Coruja). - Etym.: } \\
\text { do quíchua - khincha } \\
\text { (Granada). (Correa 1898: } \\
\text { 173) }\end{array}$ & $\begin{array}{l}\text { Regionalismo: Rio Grande } \\
\text { do Sul. } \\
\text { cobertura de palha us. tanto } \\
\text { para carros e carretas como } \\
\text { para casas. } \\
\text { Etim. hisp.-am. quincha } \\
\text { (1613) 'tecido que se faz } \\
\text { com certos vegetais', prov. } \\
\text { quích. quincha 'id. }{ }^{26}\end{array}$ & $\begin{array}{l}\text { Del quechua qincha'cerco, } \\
\text { palizada'. } \\
\text { 1. f. Arg., Ec., Perú, Ur. } \\
\text { y Ven. Tejido o trama de } \\
\text { junco con que se afianza } \\
\text { un techo o pared de paja, } \\
\text { totora, cañas, etc. }\end{array}$ \\
\hline
\end{tabular}

Tabla 2. Regionalismos riograndenses de origen platina

Además de poner de relieve la variedad de los campos semánticos en que se integran las voces recopiladas en el Vocabulario de José Romaguera Correa,

\footnotetext{
"Lo propio en la prov. brasileña de Rio Grande del Sur (Beaurepaire-Rohán)". De hecho, esta voz ya la registraba Coruja (1852: 232), cuya Colecção, en este caso, le sirve de fuente al mencionado vizconde (Beaurepaire-Rohan 1889: 117). El hecho de que Granada cite al autor brasileño prueba la existencia de conexiones entre la lexicografía hispanoamericana y la brasileña, asunto cuyo estudio, pese a ser de suma importancia para la historiografía lexicográfica del español y del portugués brasileño, no entra en los objetivos de este trabajo.

24 También recoge pulpero: "o dono ou proprietario de uma pulperia ou venda; taverneiro, etc." (Correa 1898: 169). Houaiss (2001) señala esta voz como "Regionalismo: Rio Grande do Sul. dono ou atendente de pulperia; taverneiro", marcándola como procedente del rioplatense: "plat. pulpero (1586) [...], conforme Corominas, porque a polpa de frutos tropicais era o principal artigo que podia ser vendido nas colônias espanholas na América".

25 En el Corpus del Nuevo Diccionario Histórico del Español (CNDHE), el primer registro es de 1574, por ende anterior a la fecha indicada por Houaiss.

26 En el Corpus del Nuevo Diccionario Histórico del Español, el primer registro es de 1613, la misma datación del Houaiss.
} 
la tabla 2 también muestra la coincidencia entre los significados indicados en la lexicografía contemporánea y los aducidos por el autor riograndense, demostrando asimismo que las dataciones de Houaiss toman como referencia lexicógrafos portugueses, en concreto Caldas Aulete (1881) y el ya citado Cândido de Figueiredo (ediciones de 1899 y 1922). De aquí se deduce que los redactores del Houaiss no recurrieron sistemáticamente ni a BeaurepaireRohan (1889) ni a vocabularios regionalistas brasileños -entre ellos el de Correa-, y que, por no ser un diccionario histórico, al Houaiss no se aplicaron los requisitos filológicos y lingüísticos que hoy suelen ser exigidos a una obra de esa clase. De hecho, la mayoría de los diccionarios de lengua portuguesa ni siquiera ofrece una datación o un paradigma etimológico. Aunque no tiene la pretensión de ponerle fecha al registro más antiguo de las voces, las dataciones que nos proporciona el diccionario Houaiss son, con todo, una referencia cronológica que, pese a su inexactitud, pueden ser útiles al lector. Por último, hay que subrayar que algunas de las voces recogidas por Correa como regionalismos riograndenses (véase pilcha y quincha), en realidad, según indica la marcación diatópica en el diccionario de la Real Academia, son hispanismos cuya distribución geográfica no se limita a la región platense vecina de Rio Grande, sino que circulan en otras partes de Sudamérica e incluso de Centroamérica.

\subsection{Marcación de La etimología de Las voces}

Uno de los aspectos más relevantes de la microestructura del Vocabulario Sul Rio-Grandense es la inclusión de un paradigma etimológico con una marca propia ( $E$ voc. de 'es voz de'), que suele cerrar el enunciado y, en algunos casos, dependiendo de la extensión de este, aparece antes de ciertas informaciones complementarias que Romaguera Correa añade para aclarar acepciones o discutir las opiniones de otros autores. A tenor de la influencia hispana y americana, hay que resaltar el tipo de marcación que reciben las voces de origen castellano o hispanoamericano, en especial las de origen amerindio, asimiladas por el español de la región platense y otras regiones sudamericanas. Respecto a las últimas, en la muestra recogida en la Tabla 3 se observan varias palabras marcadas como hispanoamericanismos (açoteiras, cajetilla, capincho, carpeta) y asimismo voces atribuidas a una lengua indígena (caracu, carajá). Cabe subrayar igualmente las voces que requieren, según Correa, una aclaración fonética, pues su correcta pronunciación en Rio Grande -a la española-, en lugar de la fricativa palatal del portugués, se realiza con una fricativa velar (abrojo, cajetilla, carajá). Por último, se observa que, conforme a la lexicografía actual, no todas las voces reunidas 
en la tabla son identificadas como regionalismos riograndenses; algunas son marcadas como palabras de la variedad sureña del portugués brasileño, es decir, son voces compartidas por varias regiones del país.

\begin{tabular}{|c|c|c|}
\hline $\begin{array}{r}\text { Voces y su } \\
\text { significado } \\
\end{array}$ & \begin{tabular}{|c|} 
Etimología en el \\
Vocabulario (1898) \\
\end{tabular} & $\begin{array}{c}\text { Lexicografía actual } \\
\text { Houaiss y } D L E\end{array}$ \\
\hline $\begin{array}{l}\text { Abichornar - acobardar, } \\
\text { aborrecer-se acabrunhar, } \\
\text { envergonhar: aquella } \\
\text { desgraça muito o } \\
\text { abichornou (Segundo } \\
\text { Valdez }^{27} \text {, este vocabulo } \\
\text { tem sua etymologia } \\
\text { nas palavras castelhana } \\
\text { - abochornar e } \\
\text { bochornoso, com } \\
\text { acepçao figurada de } \\
\text { corar de vergonha, } \\
\text { irritar, e o adj. com } \\
\text { a significação de - } \\
\text { vergonhoso que causa } \\
\text { vergonha e vituperio). } \\
\text { (Correa 1898: 11) }\end{array}$ & \begin{tabular}{|l|} 
Deriva do \\
castelhano \\
bochorno
\end{tabular} & $\begin{array}{l}\text { Houaiss: Regionalismo: Sul do Brasil. } \\
1899 . \\
\text { 1. tornar-se (o tempo, a atmosfera) } \\
\text { abafadiço; abochornar; 2. tornar(-se) } \\
\text { abatido; aniquilar(-se) }\end{array}$ \\
\hline $\begin{array}{l}\text { Abrojo- (o } j \text { tem o som } \\
\text { de } h \text { aspirado). } \\
\text { Especie de carrapicho. } \\
\text { (Correa 1898: 12) }\end{array}$ & $\begin{array}{l}\text { É voc. castelhano, } \\
\text { em lugar de abrolho. }\end{array}$ & $\begin{array}{l}\text { Houaiss: sin marcación diatópica } \\
\text { m.q. espinho-de-carneiro } \\
\text { ('designação comum’). } \\
\text { DLE. Planta espinosa de la familia } \\
\text { de las cigofiláceas, perjudicial } \\
\text { para los sembrados. }\end{array}$ \\
\hline $\begin{array}{l}\text { Açoiteiras - as pontas } \\
\text { das rédeas que servem } \\
\text { para castigar o cavallo. } \\
\text { No singular é usada para } \\
\text { significar extremidadedo } \\
\text { relho, ou do rebenque, } \\
\text { feita de couro. - Etym.: }\end{array}$ & $\begin{array}{l}\text { Deriv. Do castelhano } \\
\text { - azote, açoite - ou, } \\
\text { melhor, do voc. } \\
\text { hispano-americano } \\
\text { azoteras. }\end{array}$ & $\begin{array}{l}\text { Houaiss Regionalismo: Sul do Brasil. } \\
1899 \text {; } \\
\text { ponta de rebenque com que se castiga } \\
\text { o animal de montaria. } \\
\text { 2. Regionalismo: Sul do Brasil. } \\
\text { chicote curto que usam os cavaleiros } \\
\text { gaúchos }\end{array}$ \\
\hline
\end{tabular}

27 Manuel do Canto e Castro Mascarenhas Valdez (1819-1886) es el autor del Diccionario español-portugués el primero que se ha publicado con las voces, frases, refranes y locuciones usadas en España y Américas Españolas, en el lenguaje común antiguo y moderno, publicado en 1864-1866. Es el primero de la lexicografía bilingüe hispano-lusa (Vázquez 2008, 2010). 


\begin{tabular}{|c|c|c|}
\hline $\begin{array}{l}\text { Diz-se tambem çoiteiras. } \\
\begin{array}{lll}\text { (Correa 1898: } & 12)^{28}\end{array}\end{array}$ & & \\
\hline $\begin{array}{l}\text { Alambrado-terreno } \\
\text { cercado por arame. } \\
\text { (Correa 1898: 14) }\end{array}$ & $\begin{array}{l}\text { Etym.: deriv. do } \\
\text { castelhano -alambre, } \\
\text { arame. }\end{array}$ & $\begin{array}{l}\text { Houaiss (2001): que possui cerca de } \\
\text { arame. } \\
\begin{array}{l}\text { DLE: alambrado Del part. de } \\
\text { alambrar. }\end{array}\end{array}$ \\
\hline $\begin{array}{l}\text { Agalhas - Usado na } \\
\text { expressão - de agalhas: } \\
\text { este sujeito é de } \\
\text { agalhas, isto é, velhaco, } \\
\text { trampolineiro, finório e } \\
\text { tambem ironicamente } \\
\text { - parlapatão, tolo } \\
\text { presumido, fanfarrão, } \\
\text { etc. (Correa 1898: 13) }\end{array}$ & 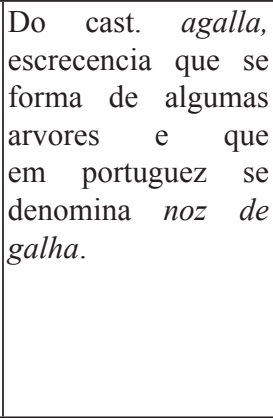 & $\begin{array}{l}\text { Houaiss Loc. } \\
\text { Regionalismo: Rio Grande do Sul. } \\
\text { Uso: informal. } \\
\text { de ganância desmedida; espertalhão, } \\
\text { velhaco. } \\
\text { esp. agalla 'amígdala; brânquia, órgão } \\
\text { de respiração dos peixes e batráquios; } \\
\text { cada um dos costados da cabeça das } \\
\text { aves; testículo; ânimo forte, valente', } \\
\text { este de orig.contrv.; as loc. são do esp. } \\
\text { sul-americano. }\end{array}$ \\
\hline $\begin{array}{l}\text { Bastos }- \text { Segundo o } \\
\text { inolvidável professor } \\
\text { Coruja, que dá como } \\
\text { subs. singular esta } \\
\text { palavra, significa ella } \\
\text { o lombilho de cabeça } \\
\text { mui rasa e pequena. } \\
\text { Temos, porém, ouvido } \\
\text { sempre empregal-a } \\
\text { para designar as partes } \\
\text { acolchoadas e paralelas } \\
\text { do lombilho. (Correa } \\
1898: 31)^{29}\end{array}$ & $\begin{array}{l}\text { É voc. cast. no } \\
\text { sentido de - albarda. }\end{array}$ & $\begin{array}{l}\text { Houaiss: Regionalismo: Sul do Brasil. } \\
\text { 1. cada uma das partes acolchoadas e } \\
\text { paralelas do lombilho que se apóiam } \\
\text { no lombo da cavalgadura; basteira, } \\
\text { suadeira, bata. } \\
\text { 2. m.q. lombilho } \\
\text { esp. plat. basto 'almofadas que } \\
\text { formam o lombilho' < lat.vulg. } \\
\text { *bastum regr. de *bastare 'levar, } \\
\text { suportar, bastar'; } \\
\text { DLE: basto m. pl. Arg., Chile, R. } \\
\text { Dom. y Ur. Almohadas que forman } \\
\text { el lomillo. }\end{array}$ \\
\hline
\end{tabular}

28 En Coruja (1852: 212) aparece esta voz. Beaurepaire-Rohan (1889: 2) toma la Colecção de ese autor como fuente, aunque para la etimología se socorre de Valdez: "Deriva-se do voc. Americano-hespanhol Azotera, que significa açoite, especie de disciplinas de varios ramos presas ás redeas do freio, e com os que suppre o chicote, para fazer apressar o passo ás cavalgaduras (Valdez)". En efecto, ese es el significado de la palabra en el Diccionario español-portugués (1864) de Valdez (1864: 333), el mismo que recoge Soares (1888/1954: 9), si bien este, además de Rio Grande do Sul, indica Rio de Janeiro.

29 Con el mismo significado y etimología castellana, Soares (1889: 85) registra esta voz en el singular (basto). 


\begin{tabular}{|c|c|c|}
\hline $\begin{array}{l}\text { Brôma- troça, caçoada, } \\
\text { gracejo. (Correa 1898: } \\
\text { 38) }\end{array}$ & $\begin{array}{l}\text { É voc. hispano- } \\
\text { americano, mais } \\
\text { usado na fronteira. }\end{array}$ & $\begin{array}{l}\text { Houaiss, (1899) dito burlesco; piada, } \\
\text { gracejo, troça; } \\
\text { esp. broma (1504) 'molusco que } \\
\text { danifica o casco de embarcações, } \\
\text { broca'; em virtude do peso do } \\
\text { casco atacado por moluscos, passa } \\
\text { a designar (1599) 'objeto pesado; } \\
\text { indivíduo pesado, estúpido', p. ext. } \\
\text { (s. XVIII) 'embuste' e 'contrariedade, } \\
\text { aborrecimento'; segundo Corominas, } \\
\text { do gr. brôma, atos 'cárie dos dentes, } \\
\text { broca, úlcera, alimento, refeição'. }\end{array}$ \\
\hline $\begin{array}{l}\text { Buenacho - Muito bom, } \\
\text { excellente, cavalheiro, } \\
\text { generoso: Moço valente } \\
\text { e buenacho. (Correa } \\
\text { 1898: 38-39) }\end{array}$ & $\begin{array}{lr}\text { Der. do cast. bueno } \\
\text { (bom), que é palavra } \\
\text { muito usada na } \\
\text { fronteira. } & \text { m.q. } \\
\text { buenaço } & \\
\begin{array}{llr}\text { aport. do plat. } \\
\text { buenazo. }\end{array} & \\
\end{array}$ & $\begin{array}{l}\text { Houaiss: Regionalismo: Rio Grande } \\
\text { do Sul. } \\
\text { m.q. buenaço. }\end{array}$ \\
\hline $\begin{array}{l}\text { Cajetilla - pelintra, } \\
\text { petit-maitre, moço de } \\
\text { cidade que anda ao sabor } \\
\text { da moda, peralvilho } \\
\text { habitante da cidade com } \\
\text { ares de presumido. } \\
\text { O j se pronuncia } \\
\text { com som guttural, à } \\
\text { hespanhola. } \\
\text { 1898: } 41)^{30}\end{array}$ & $\begin{array}{ll}\text { Voc. hispano- } \\
\text { americano }\end{array}$ & $\begin{array}{l}\text { Houaiss, Regionalismo: Rio Grande } \\
\text { do Sul. } 1899 \\
\text { 1. nas regiões rurais, homem ou rapaz } \\
\text { proveniente da cidade, que se veste } \\
\text { com esmero, na última moda; janota. } \\
\text { 2. Derivação: por extensão de sentido. } \\
\text { sujeito presumido, vaidoso, } \\
\text { exibido, que afeta importância ou } \\
\text { superioridade. } \\
\text { DLE: m. despect. coloq. Arg., } \\
\text { Par. y Ur. Hombre presumido y } \\
\text { afectado. }\end{array}$ \\
\hline
\end{tabular}

30 Esta voz también la recoge Soares como regionalismo riograndense en su Dicionário Brasileiro da Língua Portuguesa: "pelintra; "rapaz da cidade que anda no rigor da moda", aunque atribuyéndole una etimología castellana. (Soares 1889: 135)

31 Granada (1890: 141), que aduce una etimología guaraní, describe el animal con detalles propios de una definición enciclopédica: "Cuadrúpedo, de una vara aproximadamente de longitud, sin cola, de color pardo oscuro el lomo y pardo blanquizco el pecho, boca y dientes de conejo, y el cuerpo un tanto parecido al del cerdo. Habita á orillas de los ríos, arroyos y lagunas en las islas, viviendo como un anfibio, pues nada y se zambulle con frecuencia. Aprovéchase el cuero, curtiéndolo, y comen algunos charqueada la carne. Del guar, capiïba. Capibara - Capincho".

32 La datación (1898) ofrecida en Houaiss es precisamente la fecha del Vocabulario de Romaguera Correa. 


\begin{tabular}{|c|c|c|}
\hline $\begin{array}{l}\text { Capincho - a capivara } \\
\text { ou, melhor, o filho della } \\
\text { quando novo. } \\
(\text { Correa } 1898: 45)^{31}\end{array}$ & $\begin{array}{l}\text { É voc. hispano- } \\
\text { americano. }\end{array}$ & 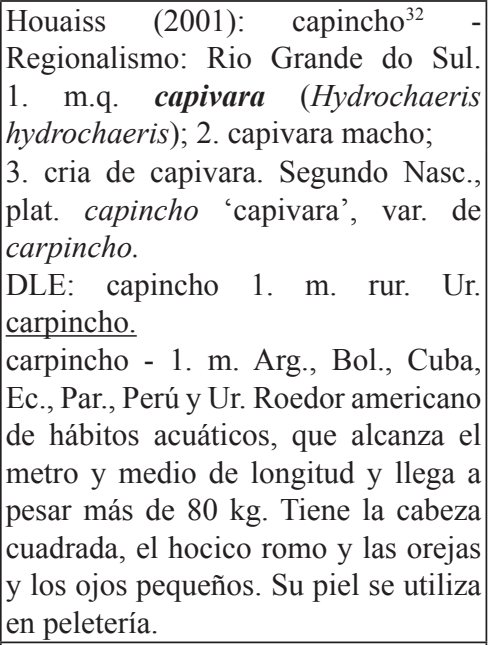 \\
\hline $\begin{array}{l}\text { Caracu - os ossos ou } \\
\text { um dos ossos da perna. } \\
\text { Significa tambem tutano } \\
\text { ou medulla dos ossos. } \\
\text { - raça de gado vacum, } \\
\text { cujo pêlo, muito curto, } \\
\text { é summanente liso. } \\
(\text { Correa } 1898: 45)^{33}\end{array}$ & $\mid$\begin{tabular}{llr} 
É & voc. & \multicolumn{2}{c}{ guarani } \\
ou, melhor, tupi \\
$($ Montoya, Voc. de \\
la lengua tupi ó \\
guarani $)^{34}$.
\end{tabular} & $\begin{array}{l}\text { Houaiss }^{35} \text { (2001) - } \\
\text { Regionalismo: Sul do Brasil. } 1 \text { o } \\
\text { tutano, a medula contida no osso } \\
\text { animal. } 2 \text { Derivação: por metonímia. } \\
\text { Regionalismo: Sul do Brasil. osso } \\
\text { com tutano. Regionalismo: Brasil. } 5 \\
\text { diz-se de ou raça bovina de pêlo liso, } \\
\text { castanho-avermelhado. } 6 \text { relativo } \\
\text { a ou o espécime dessa raça. } \\
\text { DLE - caracú. De or. guar.1. m. Arg., } \\
\text { Par. y Ur. Tuétano de los animales, en } \\
\text { particular vacunos. 2. m. Arg., Par. y } \\
\text { Ur. Hueso que contiene el caracú. }\end{array}$ \\
\hline
\end{tabular}

33 Correa discrepa de Beaureaire-Rohan (1889), autor que solo indica la acepción de "tutano" (esp. tuétano) y desconocía la segunda acepción ("osso da perna").

34 El título de la obra de Antonio Ruíz de Montoya (1585-1652) es Vocabulario de la lengua guaraní. Es probable que Correa se haya basado en Beaurepaire-Rohan (1889: 36), que cita a Montoya. Daniel Granada (1890: 143), que corrobora el origen guaraní e indica un posible étimo, además de tuétano y de hueso del tuétano, se refiere a cierta raza de ganado vacuno que, en Brasil, existiría en São Paulo, Minas Gerais y Rio Grande do Sul, información ciertamente recogida de Beaurepaire-Rohan, lexicógrafo que le sirvió de fuente respecto al léxico brasileño.

35 La datación - 1870 - se basa en la $7^{\text {a }}$ edición del diccionario de la lengua portuguesa de Morais Silva, y Houaiss supone que proceda del tupi. 


\begin{tabular}{|c|c|c|}
\hline $\begin{array}{l}\text { Carajá - especie de } \\
\text { taquara que se conserva } \\
\text { sempre verde. O } j \text { d'esta } \\
\text { palavra se pronuncia } \\
\text { com som guttural, á } \\
\text { hespanhola. (Correa } \\
\text { 1898: 46) }\end{array}$ & $\begin{array}{l}\text { É voc. hispano- } \\
\text { americano, oriundo } \\
\text { talvez do guarani. }\end{array}$ & No registrado. \\
\hline $\begin{array}{l}\text { Carancho -cara-cará, } \\
\text { certa ave de rapina. } \\
(\text { Correa 1898: } 46)^{36}\end{array}$ & $\begin{array}{l}\text { É voc. hispano- } \\
\text { americano usado no } \\
\text { Rio da Prata. }\end{array}$ & $\begin{array}{l}\text { Houaiss }(2001)^{37} \text { : Regionalismo: } \\
\text { Brasil. 1 Rubrica: ornitologia. m.q. } \\
\text { caracará (Caracaraplancus) } \\
\text { DLE: carancho. 1. m. Arg., Bol., } \\
\text { Perú y Ur. Ave del orden de las } \\
\text { falconiformes, de medio metro de } \\
\text { longitud y color general parduzco con } \\
\text { capucho más oscuro, que se alimenta } \\
\text { de animales muertos, insectos, y } \\
\text { reptiles, y vive desde el sur de los } \\
\text { Estados Unidos de América hasta } \\
\text { Tierra de Fuego. } \\
\text { 2. m. Bol. y Perú. búho (\| ave rapaz). }\end{array}$ \\
\hline $\begin{array}{l}\text { Carona-baixeira }^{38}-\text { a } \\
\text { que se colloca logo } \\
\text { imediatamente em cima } \\
\text { do xergão, abaixo da } \\
\text { segunda carona e é quasi } \\
\text { sempre de couro cru. } \\
\text { (Correa 1898: 47) }\end{array}$ & $\begin{array}{l}\text { Etym.: é palavra } \\
\text { hispano-americana. }\end{array}$ & $\begin{array}{l}\text { Houaiss (2001): } r \text { carona }^{39} \\
\text {-Regionalismo: Brasil. peça dos } \\
\text { arreios constituída por manta de } \\
\text { couro, ger. composta de duas partes } \\
\text { iguais, costuradas entre si, e que se } \\
\text { coloca no dorso da cavalgadura, sob } \\
\text { o lombilho. }\end{array}$ \\
\hline
\end{tabular}

36 Soares (1889: 111) también registra este nombre de un "pássaro que vive pelas coxilhas e pelas estradas, às vezes tristonho".

37 Para la etimologia de esta palabra, Houaiss (2001) se ayuda de las explicaciones de varios autores: "orig. contrv.; Silveira Bueno vê palavra híbrida, "formada do tupi cará 'gavião' e suf. port. ancho 'grande"'; JM e Nasc. retiram do tupi ka 'rãi 'arranhar, dilacerar com as unhas' e lembram que se trata de uma ave de rapina". Granada también recogió esta voz, aunque la hipótesis etimológica es muy distinta: "Voz imitativa. Paz-Soldán dice que en Perú llaman corancho, carancho y calancho á una especie de búho", y agrega: "En castellano capacho es el nombre de un ave nocturna semejante a una lechuza: ¿nos atreveremos a ver en calancho una corrupción de capacho, o le buscaremos el origen en alguna de las infinitas lenguas americanas? LA ETIMOLOGÍA en caracará”. (Granada 1890: 144)

38 Granada registra carona, con el significado que indica Houaiss, refiriéndose el autor también a la bajera. (Granada 1890: 147)

39 Solo recoge carona, palabra con origen en la misma forma española que nombra la 'parte do lombo da cavalgadura sobre a qual se põe a albarda'. 


\begin{tabular}{|c|c|c|}
\hline & & $\begin{array}{l}\text { DLE: (sin marca diatópica): } \\
\text { Pedazo de tela gruesa acojinado que, } \\
\text { entre la silla o albarda y el sudadera, } \\
\text { sirve para que no se lastimen las } \\
\text { caballerías. }\end{array}$ \\
\hline $\begin{array}{l}\text { Carpeta - jogo, jogatina; } \\
\text { a mesa do jogo e tambem } \\
\text { o panno com que se } \\
\text { costumam cobri-la, e } \\
\text { sobre o qual lançam as } \\
\text { cartas e as paradas os } \\
\text { jogadores. (Correa 1898: } \\
47-48)\end{array}$ & Sin marcación & $\begin{array}{l}\text { Houaiss (2001): prov. do plat. carpeta; } \\
\text { cp. esp. carpeta 'coberta, cobertura } \\
\text { de pele ou de tecido que se põe sobre } \\
\text { as mesas ou arcas' < fr. carpette; ver } \\
\text { carpete. } \\
\text { DLE: Arg., } \\
\text { Par. y Ur. Tapete verde, que cubre } \\
\text { la mesa de juego. }\end{array}$ \\
\hline $\begin{array}{l}\text { Champorrear - mal } \\
\text { preparado, grosseiro, } \\
\text { tosco, chambão, etc. } \\
\text { (Correa 1898: 51). }\end{array}$ & $\begin{array}{c}\text { É voc. da Republica } \\
\text { Argentina, derivado } \\
\text { de champorrear. }\end{array}$ & $\begin{array}{l}\text { Houaiss (2001):m.q. champirrear. } \\
\text { Regionalismo: Brasil."fabricar } \\
\text { (objeto) de maneira tosca, rústica; } \\
\text { achamboar, champorrear". } \\
\text { DLE: sin registro }{ }^{40} \text {. }\end{array}$ \\
\hline $\begin{array}{l}\text { Chucho- tremor de } \\
\text { frio, calefrio; febre } \\
\text { intermittente, sezões. } \\
\text { (Correa 1898: } 57 \text { ) }\end{array}$ & $\begin{array}{l}\text { É hispano-americano } \\
\text { usado somente nas } \\
\text { fronteiras. }\end{array}$ & $\begin{array}{l}\text { Houaiss: Regionalismo: Sul do } \\
\text { Brasil. 1. tremor de frio ou de medo; } \\
\text { calafrio; 2. Derivação: por metonímia. } \\
\text { qualquer febre intermitente. quích. } \\
\text { chuhchu 'terçã' (cp. chúchuy 'tiritar'), } \\
\text { prov. pelo plat. chucho } \\
\text { DLE: Del quechua chujchu 'frío } \\
\text { de calentura'. 1. m. Arg., Bol., } \\
\text { Par., Perú y Ur. escalofrío. }\end{array}$ \\
\hline $\begin{array}{l}\text { Compadre - pachola, } \\
\text { pernostico, cheio de si, } \\
\text { jactancioso [...] (Correa } \\
\text { 1898:). }\end{array}$ & $\begin{array}{l}\text { É voc. uruguayo } \\
\text { usado nas fronteiras. }\end{array}$ & $\begin{array}{l}\text { Houaiss (2001): Regionalismo: } \\
\text { Rio Grande do Sul. 8. que é cheio } \\
\text { de pretensões, cheio de si. } \\
\text { DLE: Arg. y Ur. compadrito. } \\
\text { Compadrito: Arg. y Ur. Tipo } \\
\text { popular, jactancioso, provocativo, } \\
\text { pendenciero, afectado en sus maneras } \\
\text { y en su vestir. }\end{array}$ \\
\hline
\end{tabular}

40 Sí recoge "champurrear" que, en el español nicaragüense, significa "obtener algo con facilidad" o "beneficiarse (\| sacar provecho)". 


\begin{tabular}{|c|c|c|}
\hline $\begin{array}{l}\text { Coscós - rosetas de } \\
\text { ferro que se colocam no } \\
\text { meio do bocal do freio } \\
\text { para fazer bulhaquando } \\
\text { o cavallo move com a } \\
\text { lingua ou morde o freio. } \\
\text { (Correa 1898: 65) }\end{array}$ & $\begin{array}{l}\text { Etym.: É corrupção } \\
\text { do castelhano }- \\
\operatorname{coscoja} a^{41} \text {. }\end{array}$ & $\begin{array}{l}\text { Houaiss - Regionalismo: Rio } \\
\text { Grande do Sul. rodela de ferro us. } \\
\text { na parte central do freio dos } \\
\text { equídeos. Etim.: plat. coscoja } \\
\text { 'id.', voc. de acp. restrita, ligado } \\
\text { ao esp. coscojo 'grão de } \\
\text { alquermes, qualquer saliência. } \\
\text { DLE:Arg. y Ur. Rueda de metal } \\
\text { colocada en el puente del freno o } \\
\text { de la brida. }\end{array}$ \\
\hline $\begin{array}{l}\text { Cusco - cão de raça } \\
\text { pequena, cão fraldeiro, } \\
\text { o mesmo que - guaypé } \\
\text { ou guaypevar O } \\
\text { diminuitivo é cusquinho } \\
\text { ou cuscosinho. Significa } \\
\text { pessoa de pequena } \\
\text { estatura e, pouca } \\
\text { importancia. }\end{array}$ & 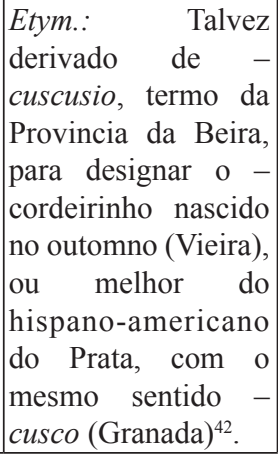 & $\begin{array}{l}\text { Houaiss (2001): Regionalismo: Rio } \\
\text { Grande do Sul. 1. cão pequeno e sem } \\
\text { raça; 2. Derivação: por extensão de } \\
\text { sentido. Uso: pejorativo. indivíduo de } \\
\text { baixa estatura e sem importância. } \\
\text { DLE: cusco - De la interj. cuz, con } \\
\text { seseo y repetida, con que se llama al } \\
\text { perro.1. m. Arg. y Ur. cuzco. cuzco De } \\
\text { cuz. 1. m. Perro pequeño. }\end{array}$ \\
\hline
\end{tabular}

Tabla 3. Marcación de la etimología (procedencia u origen) de las voces

Por otro lado, hay palabras que de inmediato denotan su origen español, como es el caso de aguateiro, aplastar o arreglar, aunque en América hayan tomado acepciones distintas, metafóricas, como sucede con aplastar, cuyo significado americano se desconoce en España. Véanse sus definiciones y compárense con lo que nos informa la lexicografía actual.

\begin{tabular}{|c|l|l|}
\hline Voces & \multicolumn{1}{|c|}{ Marca etimológica } & \multicolumn{2}{|c|}{ Lexicografía actual } \\
\hline $\begin{array}{l}\text { Aguateiro (em lugar } \\
\text { de-aguadeiro); animal } \\
\text { aguateiro é o que serve }\end{array}$ & $\begin{array}{l}\text { ou melhor do hispano- } \\
\text { americano - aguatero (D. } \\
\text { para tirar a carroça d'agua; }\end{array}$ & $\begin{array}{l}\text { Houaiss } \\
\text { Regionalismo: Sul do } \\
\text { Brasil. 1.m. q. aguadeiro } \\
\text { ('vendedor de água') }\end{array}$
\end{tabular}

${ }^{41}$ En el Vocabulario de Granada, aparece el adjetivo coscojero, ra: "dicese de la cabalgadura que hace sonar constantemente las coscojas del freno". (Granada 1890: 162)

42 En efecto, Granada recoge cuzco con el significado de "perro pequeño, labrador". (Granada 1890: 69) 


\begin{tabular}{|c|c|c|}
\hline $\begin{array}{l}\text { pessoa que se occupa nas } \\
\text { povoações em vender e } \\
\text { distribuir agua. (Correa } \\
\text { 1898: 14) }\end{array}$ & & $\begin{array}{l}\text { Regionalismo: Sul do } \\
\text { Brasil. 2. que ou o que } \\
\text { carrega água ou puxa } \\
\text { carroça de água (diz-se de } \\
\text { animal). } \\
\text { DLE - aguatero, ra. 1. Am. } \\
\text { aguador (\| persona que } \\
\text { lleva o vende agua). }\end{array}$ \\
\hline $\begin{array}{l}\text { Aplastar }- \text { diz-se em } \\
\text { relação ao cavallo no } \\
\text { sentido de cansar, porém, } \\
\text { não muito, isto é, quando } \\
\text { fica um tanto abatido, } \\
\text { esmorecido. (Correa } \\
\text { 1898: 19) }\end{array}$ & $\begin{array}{l}\text { É voc. cast. No sentido de } \\
\text { amassar, machucar, abater, } \\
\text { reduzir a plasta, deixar } \\
\text { outrem confuso. E, pois, } \\
\text { usado em sentido figurado } \\
\text { e bem podia-se, forçando- } \\
\text { se um pouco dizer que se } \\
\text { deriva do port. - } \text { plasta }^{43} \text {. }\end{array}$ & $\begin{array}{l}\text { Houaiss (2001) } \\
\text { Regionalismo: Sul do } \\
\text { Brasil. intransitivo fatigar- } \\
\text { se (com alguma coisa); } \\
\text { esfalfar-se, abater-se, } \\
\text { aplastrar. } \\
\text { DEL - 4. tr. Arg. y Ur. } \\
\text { Extenuar la cabalgadura. }\end{array}$ \\
\hline $\begin{array}{l}\text { Arreglo }- \text { combinar, } \\
\text { pôr em ordem qualquer } \\
\text { assumpto ou negocio, } \\
\text { arrumar, entrar em acordo } \\
\text { ou ajuste com outrem. } \\
\text { (Correa 1898: } 21-22)\end{array}$ & Etym.: É voc. cast. & $\begin{array}{l}\text { Houaiss } \\
\text { Regionalismo: } \\
\text { Grande do Sul. 1. ato ou } \\
\text { efeito de arreglar; ajuste, } \\
\text { combinação, acordo. } \\
\text { DLE - 1. tr. Reducir } \\
\text { o sujetar a regla, } \\
\text { ajustar, conformar. } 2 . \\
\text { tr. Componer, ordenar, } \\
\text { concertar. }\end{array}$ \\
\hline
\end{tabular}

Tabla 4. Otras voces

El Vocabulario de Romaguera Correa también ofrece información que puede ser útil para el estudio de la variación léxica en Rio Grande do Sul porque, según se estuviera más cerca o más lejos de la frontera, existirían unas voces u otras. De esa variación da fe el ejemplo siguiente: "Caldear, v. intrans.: - tomar caldo. Usado em Cima da Serra". (Correa 1898: 41)

Por último, se hará una breve referencia a las voces que, según el lexicógrafo riograndense, existen en el portugués europeo con significados distintos a los que tienen en Rio Grande do Sul. Entre los muchos ejemplos de esta clase de palabras, véanse:

43 Plasta es, según Houaiss, un "Regionalismo: Rio Grande do Sul. 1. qualquer matéria branda, moldável" y, citando a Nascentes, procede del castellano plasta ("qualquer coisa branda, como a massa, o barro etc.'); y fue vehiculado por el español platense. En el $D L E$, plasta proviene de plaste, que en griego significaba 'modelada'. 


\begin{tabular}{|c|c|}
\hline $\begin{array}{l}\text { Bomba } \\
\text { (Correa 1898: 36). }\end{array}$ & $\begin{array}{l}\text { Canudo de prata, ou de outro qualquer metal, e que se } \\
\text { introduz na cuia para se tomar o matte; tem na extremidade } \\
\text { inferior uma espécie de ralo que impede a entrada do pó da } \\
\text { herva, permitindo a passagem da agua. É voc. port. com } \\
\text { otras significações. }\end{array}$ \\
\hline $\begin{array}{l}\text { Borrachão } \\
\text { (Correa 1898: 37). }\end{array}$ & $\begin{array}{l}\text { Chifre convenientemente preparado, cujo fundo apresentando } \\
\text { um buraco, é arrolhado e a extremidade aberta. Nas viagens } \\
\text { serve para conducção de liquidos espirituosos; por cujo } \\
\text { motivo talvez tenha recebido aquella denominação. É palavra } \\
\text { portugueza com a significação de - beberrão }{ }^{44} \text {. }\end{array}$ \\
\hline $\begin{array}{l}\text { Cargueiro } \\
\text { (Correa 1898: 47). }\end{array}$ & $\begin{array}{l}\text { Maturrango; o que monta mal e que em vez de guiar é quasi } \\
\text { guiado pelo cavallo. É voc. port. em outro sentido. }\end{array}$ \\
\hline $\begin{array}{l}\text { Carretear } \\
\text { (Correa 1898: 48). }\end{array}$ & $\begin{array}{l}\text { Viajar com carretas, ter officio de carreteiro. [...]. Carregar } \\
\text { em carreta qualquer cousa. [...]. É voc. port. caído em } \\
\text { desuso. }(\text { Vieira })^{45} \text {. }\end{array}$ \\
\hline $\begin{array}{l}\text { Cevadura } \\
\text { (Correa 1898: 51). }\end{array}$ & $\begin{array}{l}\text { Cevadura de herva é a quantidade de herva-matte em pó } \\
\text { suficiente para se preparar um certo numero de cuias de } \\
\text { matte }^{46} \text {. É voc. port. mas não n'esta acepção. }\end{array}$ \\
\hline $\begin{array}{l}\text { Embonecar } \\
\text { (Correa 1898:). }\end{array}$ & $\begin{array}{l}\text { Criar espiga o milho [...]. Segundo o V. de B.-Rohan, na } \\
\text { Bahia, para indicar o mesmo facto, empregam a palavra } \\
\text { bonecar. É palavra portugueza no sentido de - adornar, } \\
\text { enfeitar, como se faz a uma bonéca (Aulete). Tambem dizem } \\
\text { - embonecrar. }\end{array}$ \\
\hline
\end{tabular}

Tabla 5. Voces portuguesas y sus acepciones riograndenses

\section{CONCLUSIONES}

El Vocabulario Sul Rio-Grandense ofrece, pese a su metodología, mucha información útil que vale la pena contrastar con la lexicografía actual y que, además, puede servir de término de comparación con fuentes primarias. En el caso de la influencia léxica del español en el léxico propio de la variedad

44 En Portugal, la palabra denomina a "aquele que bebe muito ou freq. se alcooliza; ébrio" (Houaiss 2001), correspondiente al español beberrón.

45 Se refiere al Pe. Antonio Vieira (1608-1697).

46 Como regionalismo del sur de Brasil, la acepción en Houaiss es exactamente esta. 
hablada en Rio Grande do Sul, no cabe duda de que los vocabularios regionales -entre ellos el de José Romaguera Correa- son fuentes que hay que valorar, puesto que el simple registro de las voces hispanas e hispanoamericanas constituye un marco en la historia del léxico y de la lexicografía del portugués. Heredadas del antiguo poblamiento español o de la influencia de las hablas vecinas, las voces riograndenses de origen hispano, al incorporarse al repertorio de voces de un diccionario general del portugués brasileño (e incluso en obras portuguesas del siglo XIX) o de un vocabulario regionalista, pasan a integrar la memoria léxica de la lengua, como parte de su variación y diversidad y, por ende, de la riqueza lingüística compartida con otros territorios sudamericanos. Esas voces, que son fruto del contacto multisecular entre gentes y lenguas, pueden constituir un distintivo de la cultura de una comunidad. Así sucede en Rio Grande do Sul. En efecto, los estudios dialectológicos y etnográficos corroboran la impronta hispana en Rio Grande do Sul, si bien esta no se manifieste de igual manera ni con la misma intensidad en todo el territorio riograndense. De ahí que, a finales del siglo XIX, Romaguera Correa, que siempre había vivido en ciudades fronterizas con la región platense, subrayase que el uso de ciertas voces hispanas no se extendía a todo Rio Grande do Sul, aunque seguramente su experiencia de hablante y observador de la realidad local determinó la inclusión de muchas palabras en la nomenclatura de su Vocabulario. No en vano muchos ejemplos de las tablas son hasta hoy -véanse las marcas diatópicas ofrecidas por el $D L E$ de la RAE- usados o reconocidos en las variedades hispanas de Uruguay o Argentina.

Respecto al registro lexicográfico de las voces riograndenses en obras actuales, aunque Houaiss hace buen acopio de ellas, se nota que el Vocabulario Sul Rio-Grandense no le sirvió de fuente sistemática para el registro, la marcación o la datación de las voces, por lo que valdría la pena atender más y mejor a los datos ofrecidos por esta clase de obras, sobre todo si se tiene en cuenta que el portugués no dispone todavía de un diccionario histórico equivalente al que existe para el español, y que los distintos corpus disponibles no suelen responder cabalmente a las indagaciones sobre la historia del léxico.

\section{REFERENCIAS BIBLIOGRÁFICAS}

Altenhofen, Cléo Vilson. 2006. Interfaces entre dialetologia e história. En Jacyra Mota y Suzana Alice Marcelino (orgs.). Documentos 2: Projeto Atlas Linguístico do Brasil, pp. 159-185. Salvador: Quarteto.

Aulete, Júlio Caldas. 1881. Diccionario Contemporaneo da Lingua Portugueza feito sobre um plano inteiramente novo. 2 vols. Lisboa: Imprensa Nacional. 
Balbi, Adrien. 1826. Introduction. En Atlas ethnographique du globe, ou classification des peuples anciens et modernes d'après leur langue. Partie historique et littéraire. Tome Premier. Discous préliminaire et introduction, pp.173-175. Paris: Chez Rey et Gravier Libraires.

Beaurepaire-Rohan, Visconde De. 1889. Diccionario de vocábulos brasileiros. Rio de Janeiro: Imprensa Nacional.

Bertolotti, Virginia y Magdalena Coll. 2014. Retrato lingüistico del Uruguay: un enfoque histórico sobre las lenguas. Montevideo: Universitarias. Disponible en: http://www. historiadelaslenguasenuruguay.edu.uy/15/descargar.html

Carvalho, Ana M. 2014. Linguistic continuity along the Uruguayan-Brazilian border: monolingual perception of a bilingual reality. En Laura Callahan (ed.). Spanish and Portuguese across time, place, and borders. Studies in Honour of Milton M. Azevedo, pp. 183-199. UK: Palgrave Macmillan. Doi:10.1057/9781137340450

Caviglia, Serrana y M. Fernández. 2007. Léxico y contacto: una muestra del acervo léxico compartido entre el portugués de Rio Grande del Sur y el español del Uruguay. Revista de la Academia Nacional de Letras, año 2, 3: 157-179.

Virginia Bertolotti y Magdalena Coll. 2008. La frontera Uruguay-Brasil: Análisis lingüístico de un corpus del siglo XIX. Spanish in context. Vol. 5, Issue 1, jan, 20-39. Doi: https://doi.org/10.1075/sic.5.1.03cav

Coll, Magdalena. 2009. Bilinguismo sem diglosia: O portugués e o espanhol no norte do Uruguai no século XIX. En Ana M. Carvalho (org.). Português em contacto. Linguística luso-brasileira 2, pp. 237-256. Frankfurt am Main: Vervuert/ Iberoamericana.

y Virginia Bertolotti. 2017. Voces de origen portugués en el español del Uruguay. En Dolores Corbella y Alejandro Fajardo (dir.). Español y portugués en contacto. Préstamos léxicos e interferências. Beihefte zur Zeitschrift für romanische Philologie, Band 419, pp. 231-252. Berlin/Boston: De Gruyter.

Coruja, António Álvares Pereira (1852): Colecção de vocabulos e frases usados na Provincia de São Pedro do Rio Grande do Sul. Revista do Instituto Historico e Geographico de São Paulo 16: 210-240 (2 $2^{\mathrm{a}}$ ed. London, Trübner e Comp. 1856).

Corbella, Dolores y Alejandro Fajardo (eds.). 2017. Español y portugués en contacto. Préstamos léxicos e interferencias. Beihefte zur Zeitschrift für Romanische Philologie, Bnd 419. Berlin/Boston: De Gruyter.

Correa, José Romaguera (1898): Vocabulario Sul Rio-Grandense. Pelotas/Porto Alegre: Echenique \& Irmão Editores/Livraria Universal.

ElizAincín, Adolfo. 1975. El bilingüismo de la frontera uruguayo-brasileña. Letras de Hoje 20: $65-75$.

1992. Dialectos en contacto: español y portugués en España y América. Montevideo: Arca.

2002a. Historias paralelas: español y portugués en América. En M. T. Echenique Elizondo (org.). Actas del V Congreso Internacional de Historia de la lengua española (Valencia, 31 de enero-4 de febrero de 2000), pp. 85-101. Madrid: Gredos

2002b. Diacronía del contacto español-portugués. En N. R. Díaz (org.). La Romania Americana. Procesos lingüisticos en situaciones de contacto, pp. 255-261. IberoamericanaVervuert. Madrid/Frankfurt.

2003. Testimonios sobre la peculiaridad lingüística fronteriza uruguayo-brasileña.

En F. Moreno Fernández et al. (coord.). Lengua, variación y contexto. Estudios dedicados a Humberto López Morales, pp. 605-610. Madrid: Arco Libros.

L. Behares y G. Barrios.1987. Nos falemo brasilero. Dialectos portugueses del Uruguay. Montevideo: Amesur. 
Ferreira, Manuela Barros (coord.). 2010. Bibliografia Língua e História na fronteira Norte-Sul. Mértola: Campo Arqueológico de Mértola. Disponível em: https://comum. rcaap.pt/bitstream/10400.26/4650/1/L\%C3\%ADngua_hist\%C3\%B3ria_fronteira_Norte_ Sul_bibliografia_2010.pdf

FIGUEIREDO, CÂNDIDO DE. 1899. Nôvo Diccionario da Lingua Portuguêsa. 2 vols. Lisboa: Tavares Cardoso \& Irmão ( $3^{\text {a }}$ edição 1922).

FinatTo, Maria José BoCoRny. 1993. Da lexicografia (1813-1991): tipologia microestrutural de verbetes substantivos. Dissertação de Mestrado em Língua Portuguesa. Porto Alegre: Universidade Federal do Rio Grande do Sul. Disponible en: http://www.lume.ufgrs.br/ handle/10183/147478.

Gonçalves, Maria Filomena. 2016. A ‘terminologia açucareira’ em dicionários brasileiros da língua portuguesa: o "Vocabulario Brazileiro" (1853) e o "Diccionario de Vocabulos Brasileiros" (1889). En Rosario Coluccia / Joseph M. Brincat, / Frankwalt Möhren (éd.). Actes du XXVIIe Congrès international de linguistique et de philologie romanes (Nancy, 15-20 juillet 2013). Section 5 : Lexicologie, phraséologie, lexicographie. Nancy: ATILF, pp. 293-304. Disponible en: http://www.atilf.fr/cilpr2013/actes/section-5/CILPR-20135-Goncalvez.pdf

2017. La influencia española en el Sur de Brasil: léxico riograndense y registro lexicográfico/The Spanish influence in the south of Brazil: the vocabulary of Rio Grande do Sul and its lexicographic record. En Dolores Corbella / Alejandro Fajardo (eds.). Español y portugués en contacto. Préstamos léxicos e interferencias [Spanish and Portuguese in Contact. Lexical borrowings and interferences]. Series: Beihefte zur Zeitschrift für Romanische Philologie, 419, pp. 363-391. Berlin/Boston: De Gruyter.

Granada, Daniel. ${ }^{2} 1890$. Vocabulario rioplatense razonado, precedido de un juicio crítico por D. A. Magariños Cervantes, miembro correspondiente de la Academia Española. $2^{\mathrm{a}}$ ed. corregida y considerablemente aumentada, y a la que se añade un nuevo juicio crítico publicado por D. Juan Valera, individuo de número de la Academia Española. Montevideo: Imprenta Rural.

Houarss. 2001. Dicionário Eletrônico Houaiss da Língua Portuguesa, versão 1.0. CRom. Rio de Janeiro: Instituto Houaiss/Editora Objetiva.

Koch, Walter. 1995. O povoamento do território e a formação de áreas lingüísticas. Contribuição do Atlas Lingüístico-Etnográfico da Região Sul ao estudo da fronteira lingüística entre o Brasil e o Uruguai. En Práticas de integração nas fronteiras: temas para o Mercosul, pp. 192-206. Porto Alegre: Ed. da UFRGS/ Inst. Goethe/ICBA.

M. Klashmann y C. Altenhofen. 2002. Atlas Lingüistico Etnográfico da Região Sul do Brasil, vol.1. Porto Alegre/ Florianópolis/ Curitiba: Ed.UFGRS/ Ed.UFSC/ Ed.UFPR.

LAZZARI, AlEXANDRE. 2004. Entre a grande e a pequena pátria: literatos, identidade gaúcha e nacionalidade (1869-1910). Tese de doutorado. Campinas: Universidade Estadual de Campinas/Instituto de Filosofia e Ciências Humanas. Disponible en: http://bdtd.ibict.br/ vufind/Record/CAMP_bc0d41ce61086ae7a7ee147d759edfae

Meirelles, Virginia AndreA Garrido. 2009. O português da fronteira Uruguai-Brasil. En Ana Maria Carvalho. O português em contato. V. 2. (Série Linguística Luso-Brasileira), pp. 257-275. Madrid/Frankfurt: Editora Vervuert/Iberoamericana.

Navas SÁnchez-Élez, María Victoria. 2017. Intercambios culturales y lingüísticos en la raya hispanoportuguesa: estado de la cuestión. En Dolores Corbella y Alejandro Fajardo (eds.). Español y portugués en contacto. Préstamos léxicos e interferencias (Beihefte zur Zeitschrift für romanische Philologie, Band 419), pp. 79-104. Berlin/Boston: De Gruyter.

Nascentes, Antenor. 1952/2003a. Études dialectologiques au Brésil. En Estudos filológicos, pp. 677-691. Rio de Janeiro: Academia Brasileira de Letras.

1955/2003b. Divisão dialectológica do território brasileiro. En Estudos filológicos, pp. 692-710. Rio de Janeiro: Academia Brasileira de Letras. 
Nunes, José Horta. 2006. Dicionários no Brasil. Análise e história do século XVI ao XIX. São Paulo: Pontes.

Oliveira, Ana Maria Pinto Pires de. 2001. Regionalismos brasileiros: a questão da distribuição geográfica". En Ana Maria Pinto Pires Oliveira y Aparecida Isquierdo Negri (orgs). As ciências do léxico, lexicologia, lexicografia, terminologia. $2^{a}$ ed., pp. 109-115. Editora UFMS: Campo Grande.

Ramírez Luengo, José Luis. 2005. Contacto hispano-portugués en la Romania Nova: aproximación a la influencia portuguesa en el español uruguayo del siglo XIX. Res Diachronicae 4: 115-132.

2006. Sobre la influencia del portugués en el español uruguayo del siglo XIX: el lusismo léxico y su especificidad en el marco rioplatense. En D. da Hora (org.). Línguas(s) e povos: unidade e diversidade, pp. 143-149. João Pessoa: Idéia.

Real Academia Española. Corpus del Nuevo Diccionario Histórico del Español. Disponible en: http://web.frl.es/CNDHE/org/publico/pages/ayuda/ayuda.view

Diccionario de Lengua Española. Disponible en: https://dle.rae.es/?w=diccionario

Rodríguez, Zorobabel. 1875. Diccionario de chilenismos. Santiago: Imprenta de "El Independiente".

Ruiz de Montoya, Antonio. 1640. Arte, e Bocabulario de la lengua guaraní por el Padre Antonio Ruiz de la Compañia de Jesús. Madrid: Juan Sánchez.

Soares, António Joaquim de Macedo. 1889. Diccionario brasileiro da lingua portugueza. Rio de Janeiro: Typ. de G. Leuzionger \& Filhos.

Valdez, Manuel do Canto e Castro Mascarenhas. 1864-1866. Diccionario españolportugués el primero que se ha publicado con las voces, frases, refranes y locuciones usadas en España y Américas Españolas, en el lenguaje común antiguo y moderno. 3 vols. Lisboa: Imprensa Nacional.

VÁzquez, Ignacio. 2008. Lexicografía bilingüe hispano-lusa: Mascarenhas Valdez. Tesis doctoral. Alicante: Biblioteca Virtual Miguel de Cervantes. Disponible en: http://www. cervantesvirtual.com/obra/lexicografia-bilingue-hispanolusa-mascarenhas-valdez--0/

2010. El primer diccionario español-portugués: una obra el siglo XIX producto de las ideas sociales del iberismo. En Marta Concepción Ayala Castro y Antonia María Medina Guerra (ed. y coord.). Diversidad lingüistica y diccionario, pp. 439-449. Málaga: Universidad de Málaga. 